\title{
Review Article \\ Relevance of the Glutathione System in Temporal Lobe Epilepsy: Evidence in Human and Experimental Models
}

\author{
Noemí Cárdenas-Rodríguez, ${ }^{1}$ Elvia Coballase-Urrutia, ${ }^{1}$ \\ Claudia Pérez-Cruz, ${ }^{2}$ Hortencia Montesinos-Correa, ${ }^{3}$ Liliana Rivera-Espinosa, ${ }^{4}$ \\ Aristides Sampieri III, ${ }^{5}$ and Liliana Carmona-Aparicio ${ }^{1}$ \\ ${ }^{1}$ Laboratory of Neurochemistry, National Institute of Pediatrics, 04530 Mexico City, Mexico \\ ${ }^{2}$ Laboratory of Neuroplasticity and Neurodegeneration, CINVESTAV, 07360 Mexico City, Mexico \\ ${ }^{3}$ Service of Endocrinology, National Institute of Pediatrics, 04530 Mexico City, Mexico \\ ${ }^{4}$ Laboratory of Pharmacology, National Institute of Pediatrics, 04530 Mexico City, Mexico \\ ${ }^{5}$ Department of Comparative Biology, Faculty of Sciences, National Autonomous University of Mexico, 04150 Mexico City, Mexico
}

Correspondence should be addressed to Aristides Sampieri III; aris_sampieri@yahoo.com.mx and Liliana Carmona-Aparicio; c_apariccio@yahoo.com.mx

Received 15 September 2014; Accepted 11 November 2014; Published 30 November 2014

Academic Editor: Elisa Cabiscol

Copyright @ 2014 Noemí Cárdenas-Rodríguez et al. This is an open access article distributed under the Creative Commons Attribution License, which permits unrestricted use, distribution, and reproduction in any medium, provided the original work is properly cited.

\begin{abstract}
Oxidative stress, which is a state of imbalance in the production of reactive oxygen species and nitrogen, is induced by a wide variety of factors. This biochemical state is associated with diseases that are systemic as well as diseases that affect the central nervous system. Epilepsy is a chronic neurological disorder, and temporal lobe epilepsy represents an estimated $40 \%$ of all epilepsy cases. Currently, evidence from human and experimental models supports the involvement of oxidative stress during seizures and in the epileptogenesis process. Hence, the aim of this review was to provide information that facilitates the processing of this evidence and investigate the therapeutic impact of the biochemical status for this specific pathology.
\end{abstract}

\section{Oxidative Stress: Antioxidant Defense Mechanisms}

Mitochondria are the organelles responsible for most ATP production in nonphotosynthetic organisms. Mitochondria produce energy by oxidizing carbohydrates and fats through the tricarboxylic acid (TCA) cycle and $\beta$-oxidation, respectively. Electrons from nicotinamide adenine dinucleotide phosphate (NADH) and the reduced form of flavin adenine dinucleotide $\left(\mathrm{FADH}_{2}\right)$, which are produced through the TCA cycle, are transferred to the electron transport chain in the inner mitochondrial membrane. Although the primary function of mitochondria is to produce ATP, they are also critically involved in the control of apoptosis and calcium homeostasis as well as the production and detoxification of reactive oxygen species (ROS) [1].
The physiological levels of ROS can be scavenged by enzymatic (e.g., superoxide dismutase (SOD), glutathione peroxidase $(\mathrm{GPx})$, glutathione reductase $(\mathrm{GR})$, and catalase (CAT)) and nonenzymatic (e.g., vitamin C, vitamin E, carotene, coenzyme $\mathrm{Q}$, melatonin, and reduced forms of glutathione (GSH)) antioxidant defense systems. However, excessive ROS levels caused by increased ROS production or decreased antioxidant defense can lead to oxidative stress [2], which damages proteins, phospholipids, and mitochondrial DNA and results in cell death [3].

Antioxidants can delay or prevent the oxidation of a substrate [4]. The physiological production of ROS in aerobic organisms requires the presence of a defense system to protect against the effects of these oxidative species. This antioxidant defense system has two parts: high molecular weight (antioxidant enzymes, including SOD, CAT, and peroxidases) and 
low molecular weight (nonenzymatic antioxidants, including vitamins, lipoic acid, uric acid, and GSH) [5].

1.1. GSH: Activity of Antioxidant Enzymes. GSH is involved in the activity of the antioxidant enzymes GPx, GR, and GST.

(a) GPx is a selenoenzyme that catalyzes the reduction of two molecules of peroxide using reduced GSH, and it is found in several isoforms [6-9]. Cytosolic GPx (cGPx, GPx-1) is present in the cytosol of all tissues at different concentrations. Plasma GPx (pGPx, GPx-3) occurs in the extracellular fluid of various tissues and in high concentrations in the kidney. Phospholipid GPx (PHGPx, GPx-4) in the membrane and cytosol of various tissues functions as an antioxidant in the cell membrane, and it is abundant in testicles. Gastrointestinal GPx (GI-GPx, GPx-2) is present in the cytosol of the liver and intestinal tract of humans.

(b) The GR enzyme is found in the cytoplasm and has an FAD+ coenzyme at its active site, and it catalyzes the reduction of glutathione disulfide (GSSG) using the coenzyme NADPH [10]. Evidence indicates that NADPH reduces $\mathrm{FAD}^{+}$, which transfers two electrons to the disulfide linkage (-S-S-) between two active site cysteine residues. The two - $\mathrm{SH}$ groups that are formed then interact with GSSG, reducing it to two GSH molecules. GR maintains the GSH levels in the cell [11].

(c) GSH S-transferase (GST) is an enzyme that is found as cytosolic and microsomal isoforms. Cytosolic GST is divided into four main families $(\alpha, \mu, \pi$, and $\theta)$ and four minor families $(\zeta, \sigma, \kappa$, and $\omega)$, whereas microsomal GST is divided into three families (MGST1, MGST2, and MGST3). Cytosolic GST consists of two identical protein subunits, whereas microsomal GST is a trimer [12-14]. The principal function of this enzyme is the conjugation of GSH with numerous organic compounds; GST can also reduce lipid hydroperoxides, such as GPx, and may detoxify 4-hydroxynonenal (4HNE), a product of lipid peroxidation.

\section{Role of GSH in Neurodegenerative Diseases}

Currently, the etiology of neurodegenerative disease lacks an explanation. Many nervous system (NS) disorders are followed by cognitive function deterioration. Among these neurodegenerative processes, a progressive loss of specific neuronal populations is observed, resulting in scenarios in which ROS play a central role. However, the neuronal death that occurs because of trauma, ischemia, inflammatory lesions, excitotoxicity, and excessive ROS may trigger the degenerative process in certain diseases, such as Alzheimer's disease $(A D)$ [15, 16], Parkinson's disease (PD) [15, 17], Huntington's disease (HD) $[15,18,19]$, amyotrophic lateral sclerosis (ALS) [20-22], Friedreich's ataxia (FRDA) [23, 24], and epilepsy [25-27]. These diseases manifest a number of complications, including impaired cognition, motor function, and dementia.

The brain is particularly vulnerable to oxidative stress because of its high oxygen consumption; in addition, it contains unsaturated fatty acids that are targets of lipid peroxidation [28-30]. GSH is synthesized in brain cells, and intracellular concentrations have been observed in the range of 0.2 to $10 \mathrm{mM}$ [31]. In 1989, Chen et al. reported GSH levels in different brain regions (i.e., cortex $>$ hippocampus $>$ brainstem) and showed results similar to those reported by Abbott et al. $[32,33]$. The GSH level in the cerebrospinal fluid (CSF) is much lower $(\sim 5 \mu \mathrm{M})$ than in brain tissue $[34,35]$. GSH depletion can enhance oxidative stress and may also increase the levels of excitotoxicity molecules, and both actions can initiate cell death in distinct neuronal populations. Similarly, GSH plays multiple roles in the NS, including that of a free radical scavenger, redox modulator of ionotropic receptor activity, and possible neurotransmitter.

The involvement of GSH in neuronal diseases was first described in the neuronal ceroid lipofuscinoses (NCLs), which is known as Batten disease. In an initial study, the formation of pathological "lipopigments" was observed, which was possibly because of an increased rate of peroxidation of polyunsaturated fatty acids [36]. Subsequent research has shown that, in the blood cells of patients with NCLs, the loss of oxidant enzymes is different from that in the controls $[37,38]$. The loss of GSH is considered an early change that is responsible for the increased susceptibility to oxidative stress, and it is also associated with aging and leads to neuronal degeneration.

Numerous studies have been conducted to determine the role of GSH in PD, AD, HD, ALS, FRDA, and epilepsy. Pearce et al. were the first to determine that the GSH content in the substantia nigra is significantly lower than in other brain regions [39]. Similar results were obtained in autopsied human brains with PD [40, 41]. In addition, disturbances in brain GSH metabolism may contribute to the development of AD and PD [42-44]. In 2005, Liu et al. showed for the first time that GSH metabolism was regulated differently in male and female AD patients [45].

Furthermore, the reduction of GSH has been reported in the spinal cord in a mouse model of ALS [46]. GSH metabolism disorders might be key risk factors for ALS. Numerous clinical studies have reported an altered redox cycle in ALS patients, including alterations in the synthesis of GPx and activities of other antioxidative enzymes. One study of 35 sporadic ALS patients revealed significantly decreased activities of both GPx and CuZn SOD in the ALS patients compared with that of the controls [47], and additional studies have shown similar results $[48,49]$. In postmortem brain samples from 9 patients with sporadic ALS, GPx activity was shown to be reduced in a brain region that is affected in patients with ALS [50].

Reduced GSH and oxidized GSH (GSSG) levels were also observed in various brain areas (substantia nigra, putamen, caudate nucleus, globus pallidus, and cerebral cortex) of patients with $\mathrm{HD}$, and reduced GSSG levels were observed in the caudate nucleus (50\%) [51]. In another study, the lipid peroxidation levels were higher and the GSH levels were lower in the plasma of HD patients compared to ageand gender-matched controls [52]. Finally, animal models of $\mathrm{HD}$ have shown a significant increase in GSH content in mitochondria isolated from the cortex, striatum [53], hippocampus, and cortex [54]. 


\section{Oxidative Stress in Epilepsy: Relevance of GSH}

Dysregulation of GSH homeostasis and alterations in GSHdependent enzyme activities are increasingly implicated in the induction and progression of neuronal diseases, such as epilepsy. It has been widely reported that alterations in the antioxidant system and increases in oxidants are associated with this condition. Epilepsy is one of the most common and serious brain disorders, and it affects at least 50 million people worldwide [55]; in addition, approximately 100 million people will have at least one epileptic seizure during their lifetime.

The brain is particularly susceptible to oxidative stress because it is the organ that utilizes the greatest amount of oxygen within the body. A high content of polyunsaturated fatty acids susceptible to lipid peroxidation, high iron content capable of catalyzing hydroxyl radical formation, and low amounts of CAT increase the susceptibility of the brain to damage from excessive oxidative stress. Oxidative stress is regarded as a possible mechanism in the pathogenesis of epilepsy [56]. Furthermore, persistent seizures have been demonstrated to cause cell damage through increases in oxidative stress [57-61]. As described below, several animal models of epilepsy have consistently found significant increases of ROS after seizures, and important alterations in the antioxidant system have been found in seizing animals and epileptic patients.

Clinical studies have also demonstrated that epileptic patients show a higher lipid peroxidation rate and lower concentrations of vitamins $\mathrm{C}$ and $\mathrm{A}$ in plasma compared with healthy controls. In one study, epileptic patients treated with phenobarbital and who did not present with convulsions for one year had higher GR levels compared with their pretreated conditions, suggesting that free radicals may be implicated in epilepsy [62]. Other studies have found low levels of selenium (Se) and GPx in patients with epilepsy $[63,64]$, indicating that impairments in the antioxidant system are highly implicated in seizure generation and recurrence.

3.1. Discovering the Relevance of GSH in Epileptic Seizures through the Use of Animal Models. Genetically epilepsyprone rats (GEPRs) are models of generalized tonic/clonic epilepsy. GEPRs-9 animals develop severe seizures, resulting in hind limb extension [65]. In these animals, hippocampal development is accompanied by oxidative stress, and GEPRs9 animals cannot compensate for a breakdown in GPx enzymatic activity. These animals show a decrease in GPx and the GSH/GSSG ratio and an increase in GSSG, lipid peroxidation, and protein oxidation, suggesting that the enhanced oxidative burden in GEPR-9s may be caused by their failure to respond to reduced GPx along with the perturbed GSH status in this strain [66].

The administration of systemic of trimethyltin (TMT) in rat models results in a pattern of damage in the CA3 hippocampal region [67] and dentate gyrus [68]. TMT administration generates phenotypes that are similar to phenotypes in certain human epileptic patients, including seizure susceptibility, hyperactivity, and aggression [69]. TMT decreases the ratio of GSH to GSSG, GSH-immunoreactivity, and GPx and GSH protein expression levels in rat hippocampi [70]. However, an elevation in GSH S-transferase (GST) activity has been observed in the hippocampi of mice treated with TMT, suggesting that GST activation may be responsible for the reduced levels of GSH found in the hippocampus [71]. The above data suggest important alterations in the antioxidant system in seizing animals, specifically the GSH defense system. Decreased enzymatic activity is observed after seizures, and if it is restored, seizures can be reduced.

3.2. Antiepileptic Drugs and Oxidative Stress in Epileptic Patients. Several studies have demonstrated that antiepileptic drugs (AEDs) may impair the antioxidant defense system and induce or exacerbate oxidative injury in epileptic patients. Several first-choice AEDs for epileptic syndromes, such as valproic acid, carbamazepine, phenytoin, and phenobarbital, increase lipid peroxidation and nucleic acid oxidation in the blood [72-78]. In addition, phenytoin decreases the GSH serum levels in adult epileptic patients, carbamazepine reduces GPx levels, and phenobarbital decreases SOD and GPx levels in the erythrocytes of adult patients [76]. Carbamazepine has also been shown to induce fewer disturbances to antioxidant and lipid peroxidation relative to valproic acid $[74,75]$ or phenytoin [76].

Alterations in the antioxidant system induced by AED therapy can be explained by the metabolism of AED into reactive epoxide intermediates, which bind covalently to bimolecular and induce structural and functional impairments [79]. AED treatment has also been associated with cognitive decline $[80,81]$, and high doses increase the risk of cognitive side effects $[82,83]$. Therefore, researchers are now focusing on developing add-on treatments for AED therapies to counteract the cognitive decline induced by antiepileptics and seizures. In various studies, a beneficial effect of melatonin as an add-on therapy for epileptic children was described in a series of clinical trials [84-87]. In addition, the add-on melatonin treatment was reported to elevate GR and GPx activities in the blood of epileptic children receiving valproic acid or carbamazepine monotherapy $[85,86]$. These authors also observed that melatonin improved sleep patterns, behavior, attention, cognition, and memory function in epileptic children receiving valproic acid monotherapy, which may reflect a neuroprotective effect of melatonin against the deleterious effects of epilepsy and AED therapy $[85,86]$.

In another study, topiramate (TPM), a new antiepileptic compound that acts by inhibiting voltage-gated sodium and calcium channels, blocking glutamate AMPA/kainite receptors and enhancing $\mathrm{GABA}_{\mathrm{A}}$ receptor-mediated chloride, was tested as a neuroprotective agent [88]. TPM therapy in combination with selenium supplementation (TPM $+\mathrm{Se})$ decreases erythrocyte lipid peroxidation and increases GSH and GSH-GPx along with plasma vitamins $\mathrm{A}$ and $\mathrm{C}$ in refractory epileptic patients [89]. Moreover, in pentylenetetrazol- (PTZ-) treated rats, TPM and TPM + Se decreased lipid peroxidation in plasma and erythrocytes and increased 
TABLE 1: Evidence of the GSH system in experimental epilepsy models.

\begin{tabular}{|c|c|c|c|}
\hline Model & Procedure model & Observations & References \\
\hline $\begin{array}{l}\text { Electrical implants in male } \\
\text { Sprague-Dawley rats } \\
(300-500 \mathrm{~g})\end{array}$ & $\begin{array}{l}\text { Insulated stainless steel electrodes were } \\
\text { implanted in the left dentate gyrus and } \\
\text { angular bundle. } \\
\text { During the experiments, video-EEG was } \\
\text { continuously recorded ( } 24 \mathrm{~h} \text { /day) until the } \\
\text { animals were sacrificed. } \\
\text { Plasma was used by biochemical } \\
\text { determinations. }\end{array}$ & $\begin{array}{l}\text { The glutathione PEGylated (GSH-PEG) } \\
\text { liposomal methylprednisolone (MP) } \\
\text { treatment did not have any effect on SE } \\
\text { duration and subsequent seizure } \\
\text { development. Both the GSH-PEG liposomal } \\
\text { MP-treated and vehicle-treated rats } \\
\text { developed spontaneous seizures, indicating } \\
\text { that GSH-PEG liposomal MP could not } \\
\text { prevent epileptogenesis. }\end{array}$ & {$[108]$} \\
\hline $\begin{array}{l}\text { Hippocampal glutamine } \\
\text { synthetase deficiency by } \\
\text { continuous microinfusion } \\
\text { of methionine sulfoximine } \\
\text { (MSO) in male } \\
\text { Sprague-Dawley rats } \\
\text { (180-220 g) }\end{array}$ & $\begin{array}{l}\text { An osmotic pump was introduced through a } \\
\text { burr hole in the skull and then into the right } \\
\text { hippocampus. The pumps were filled with } \\
\text { MSO to achieve the following drug delivery } \\
\text { rates: } 2.5,1.25 \text {, and } 0.625 \mu \mathrm{g} / \mathrm{h} \text { for } \\
\text { approximately } 28 \text { days. Separate pumps were } \\
\text { filled with saline }(0.9 \% \mathrm{NaCl}) \text { as a control. } \\
\text { For the GSH determination, the hippocampi } \\
\text { were isolated. } \\
\text { GSH was measured using the } \\
\text { spectrophotometric method with } \\
\text { 5-thio-2-nitrobenzoic acid in a reaction } \\
\text { coupled with GR. }\end{array}$ & $\begin{array}{l}\text { Recurrent behavioral seizures occurred with } \\
\text { all doses of MSO. } \\
\text { The intrahippocampal infusion of MSO was } \\
\text { associated with a dose-dependent loss of } \\
\text { neurons in the hippocampal formation and } \\
\text { nearby brain areas. } \\
\text { No decrease in hippocampal GSH was } \\
\text { observed in the lower-dosed animals } \\
(0.625 \mu \mathrm{g} / \mathrm{h}) \text {, whereas a } 21 \% \text { decrease was } \\
\text { observed in the higher-dosed animals } \\
(2.5 \mu \mathrm{g} / \mathrm{h}) 10 \text { days after the onset of MSO } \\
\text { infusion. }\end{array}$ & [109] \\
\hline
\end{tabular}

Lithium chloride ( $\mathrm{LiCl})(127 \mathrm{mg} / \mathrm{kg})$ was injected intraperitoneally (i.p.) into both the experimental and control groups. Status epilepticus (SE) was induced by a subcutaneous injection of pilocarpine

Lithium-pilocarpine in male Sprague-Dawley rats (260-300 g)

Pilocarpine in 7- to 8-week-old male CD1 mice (25-40 g) hydrochloride $(25 \mathrm{mg} / \mathrm{kg}) 20 \mathrm{~h}$ after the $\mathrm{LiCl}$ treatment. For the GSH determination, the hippocampus, dentate gyrus, amygdala, entorhinal, piriform cortices (hippocampal formation), cerebral cortex, and cerebellum were removed and evaluated by high-performance liquid chromatography (HPLC).

A single dose of pilocarpine was administered (330-345 mg/kg subcutaneously). All determinations with pilocarpine and controls were realized within 3.5-4 weeks after treatment, and the cerebral cortices, HF, and blood samples were obtained.

The GSH levels were measured by HPLC.

The control animals received $0.9 \%$ i.p. saline, and in the experimental group, the animals were treated with a dose of pilocarpine hydrochloride (400 mg/kg, i.p.).

Pilocarpine in 2-month-old male Wistar rats (250-280 g)
To determine the lipid peroxidation level, nitrite content, GSH concentration, and SOD and CAT activities, the rats (pilocarpine and control groups) were sacrificed $24 \mathrm{~h}$ after the treatment, and the brains were dissected on ice to remove the frontal cortex and striatum.
The concentration of GSH was decreased in the hippocampal formation (22.6\%) and cerebellum (6\%) in the epileptic rats.

The level of GSH was significantly decreased $(18 \%)$ in the hippocampal formation, whereas it was not significantly altered in the cortex in the pilocarpine mice.

After pilocarpine-induced SE, significant increases (i.e., 47 and 59\%) in the thiobarbituric acid reactive substance (TBARS) levels in the striatum and frontal cortex were observed. Marked increases were presented in nitrite content: 49 and $73 \%$ in the striatum and frontal cortex, respectively; the GSH concentrations decreased by 54 and $58 \%$ in the striatum and frontal cortex, respectively; the SOD in frontal cortex was verified by its increase of $24 \%$ after the seizures; and CAT increases of 39 and $49 \%$ were observed in the striatum and frontal cortex, respectively. 
TABle 1: Continued.

\begin{tabular}{|c|c|c|c|}
\hline Model & Procedure model & Observations & References \\
\hline $\begin{array}{l}\text { Pilocarpine-lithium in } 80 \text { - } \\
\text { to } 90 \text {-day-old male and } \\
\text { female Wistar rats }\end{array}$ & $\begin{array}{l}\text { SE was induced by administering } \\
\text { pilocarpine hydrochloride ( } 30 \mathrm{mg} / \mathrm{kg} \text { i.p.) } \\
22 \mathrm{~h} \text { after LiCl ( } 127 \mathrm{mg} / \mathrm{kg} \text { i.p.). SE was } \\
\text { interrupted after } 2 \mathrm{~h} \text {, and the rats were } \\
\text { sacrificed } 24 \mathrm{~h} \text { later. The piriform and } \\
\text { entorhinal cortices, temporal neocortex, } \\
\text { thalamus, and hippocampus were dissected. } \\
\text { Neurochemical determinations were } \\
\text { performed using spectrophotometric } \\
\text { methods: lipid peroxidation was analyzed by } \\
\text { measuring the TBARS levels; SOD activity } \\
\text { was analyzed with the xanthine-xanthine } \\
\text { oxidase system, and GPx was analyzed by } \\
\text { reducing the cumene hydroperoxide using } \\
\text { GSH as a reducing agent. }\end{array}$ & $\begin{array}{l}\text { The TBARS levels in all of the examined } \\
\text { structures were significantly higher in the } \\
\text { rats with SE: approximately } 41 \% \text { higher in } \\
\text { the piriform and entorhinal cortices; } 22 \% \\
\text { higher in the temporal neocortex; } 25.7 \% \\
\text { higher in the thalamus and } 15 \% \text { higher in } \\
\text { the hippocampus. SOD activities were } \\
\text { significantly higher in the rats with SE in the } \\
\text { piriform and entorhinal cortices (11.7\%) and } \\
\text { temporal neocortex (19.7\%). } \\
\text { The GPx activities were significantly higher } \\
\text { in the animals with SE in the piriform and } \\
\text { entorhinal cortices ( } 22.1 \%) \text { and thalamus } \\
\text { (8.9\%). The authors did not observe } \\
\text { significant sex-treatment interactions in the } \\
\text { results in any of the investigated brain } \\
\text { regions. }\end{array}$ & {$[113]$} \\
\hline
\end{tabular}

The experimental group was injected with pilocarpine $(350 \mathrm{mg} / \mathrm{kg}$ i.p.), and the control rats were injected with a physiological salt solution. The rats were sacrificed by decapitation $2 \mathrm{~h}$ after drug administration, and the cortical regions were removed. Neurochemical determinations were performed by spectrophotometric methods: lipid peroxidation was analyzed by measuring the oxidative marker Pilocarpine in male Wistar rats $(250-350 \mathrm{~g})$

Kainite in male Sprague-Dawley rats (300-350 g) malondialdehyde (MDA); SOD activity was measured with the xanthine/xanthine oxidase system; GPx was measured with $\mathrm{H}_{2} \mathrm{O}_{2}$ as the substrate and GR and NADPH as the enzymatic and nonenzymatic indicators, respectively; CAT activity was measured by $\mathrm{H}_{2} \mathrm{O}_{2}$ decomposition and GR and NADPH as the enzymatic and nonenzymatic indicators, respectively. The mRNA expression of the antioxidant enzymes was determined by real-time RT-PCR.

The rats were subcutaneously administered saline or $11 \mathrm{mg} / \mathrm{kg}$ kainite. The rats were sacrificed after $1 \mathrm{~min}$ of carbon dioxide inhalation and then were immediately decapitated at 8 h, 24 h, 48 h, 1 week, 3 weeks, and 6 weeks after injection to determine the acute, latent, and chronic periods of epileptogenesis. The hippocampal tissue was prepared for biochemical analysis. GSH and GSSG were determined by HPLC.
Pilocarpine increased the MDA levels (64\%). All enzymatic activities were measured, and CAT, GPx, and SOD significantly increased in response to pilocarpine $(28 \%, 28 \%$, and $21 \%$, resp.). The GPx gene expression significantly increased in the pilocarpine group (1.47-fold), and the Mn-SOD expression also significantly increased (1.33-fold). The CAT expression was unchanged.
Whole hippocampal tissue GSH decreased during the acute, latent, and chronic stages of the experimental temporal lobe epilepsy (TLE).

Hippocampal tissue GSSG levels increased substantially at $48 \mathrm{~h}$ after kainate treatment. Acute GSSG was increased at the 8 and $24 \mathrm{~h}$ time points. During the latent period, GSSG was elevated from 1 to 6 weeks after the kainite treatment. The GSH/GSSG ratio was significantly decreased in the kainate treatment groups from $24 \mathrm{~h}$ through 6 weeks.
GSH levels compared with that of the control group [90]. Therefore, TPM appears to be a promising new AED that not only ameliorates epileptic seizures but also can shield the brain from the damaging effects of oxidative stress.

\section{GSH in Temporal Lobe Epilepsy}

The evidence for GSH involvement in epilepsy is well known, and we have provided evidence of such involvement in experimental models (Table 1) as well as in humans (Table 2). 


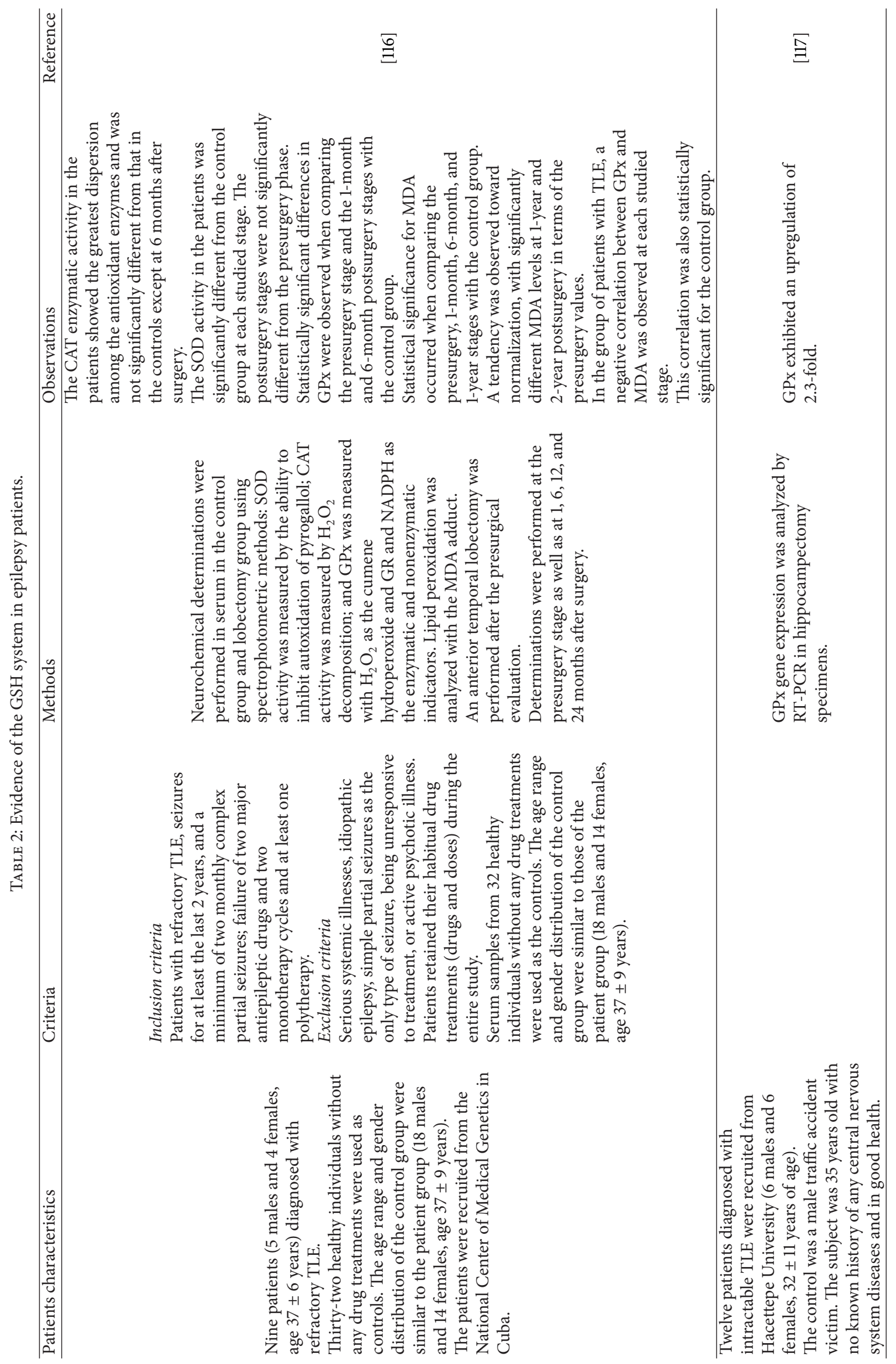




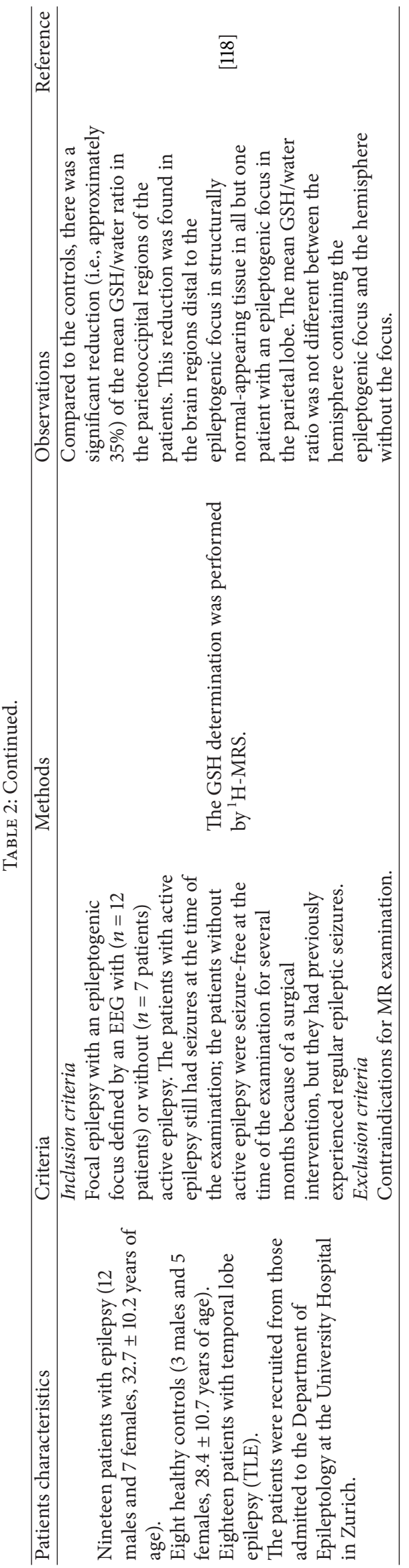




\section{Potential Use of Antioxidants against Seizures and Their Epileptogenic Impact on the GSH}

Current research has suggested that antioxidant compounds may provide some level of neuroprotection against the neurotoxicity of seizures at the cellular level. Epigallocatechin-3gallate (EGCG) is the main polyphenol of green tea and possesses important antioxidant, anti-inflammatory, and antiapoptotic properties [91-93]. Recently, it has been demonstrated that EGCG suppresses the progression of kindling and ameliorates the cognitive impairment in PTZ-kindled rats [94]. Moreover, EGCG treatment restores the oxidative stress induced by PTZ-kindling by increasing brain GSH levels [94].

During the last decade, curcumin has been the focus of attention in the field of antioxidant and anti-inflammatory research because of its promising effects in several diseases. Curcumin is a low molecular weight polyphenol found in the dried ground rhizome of the perennial herb Curcuma longa [95]. Recently, it has been tested for its neuroprotective properties in neurodegenerative diseases, such as $\mathrm{AD}$ [96], and it has also been tested as an anticonvulsant and cognitive enhancer. As previously mentioned, AED treatment has been associated with cognitive decline, and Reeta et al. investigated the neuroprotective effect of curcumin against phenytoininduced cognitive impairment in rats [97]. These authors observed that curcumin produced a dose-dependent reduction of phenytoin-induced brain malondialdehyde (MDA) and dose-dependent increase in GSH brain levels. These effects were accompanied by positive effects on retention transfer latency in an elevated plus maze test and the passive avoidance paradigm. Moreover, curcumin alone (administered for 21 days) decreased oxidative stress levels, which was indicated by a significant decrease and increase in brain MDA and GSH levels, respectively [97]. Several studies have focused on the antiepileptic actions of curcumin, which has also been shown to have anticonvulsant properties against seizures induced by $\mathrm{KA}[98,99]$ and $\mathrm{FeCl}_{3}[100]$ and an ability to elevate the seizure threshold in the maximal electroshock model [101]. In addition, curcumin can reduce the incidence of status epilepticus induced by pilocarpine [102] and inhibits amygdala-kindled seizures in rats [103]. Moreover, curcumin restores pilocarpine-induced decreases in hippocampal GSH and SOD levels [102], indicating that enhancing the antioxidant system may be a potential strategy to combat epileptic seizures.

\section{Other Antiepileptic Therapies That Regulate GSH Levels}

The classic ketogenic diet (KD) is a high-fat/low-carbohydrate diet (most often in a 4:1 fat: nonfat ratio) that is used to treat intractable seizures in children and adolescents. Our understanding of the metabolic effects of a $\mathrm{KD}$ originates from the pioneering work of Cahill and colleagues in the 1960s, but the importance of these diets from a clinical perspective was acknowledged in the early 1920s with their successful use in the treatment of epilepsy.
Several theories have focused on the potential protective role of ketone bodies that accumulate during ketosis; recently, an alteration in mitochondria bioenergetics caused by the application of a KD has been suggested. GSH levels are an important indicator of mitochondrial and cellular health, and as mentioned above, mitochondrial dysfunction has been implicated in seizures and epilepsy.

Mice fed a KD for 10-12 days have been shown to produce less ROS [104]. In addition, rats maintained on a $\mathrm{KD}$ for at least 4 weeks have been found to have significantly more mitochondria in their hippocampi compared with that of controls, suggesting that mitochondrial biogenesis is stimulated by the consumption of a KD [105]. Several markers of redox status, such as increases in the GSH/GSSG ratio, have shown improvement in the hippocampi of rats fed a KD [106]. Furthermore, the increased activity of glutamate cysteine ligase (GCL), the rate-limiting enzyme in GSH biosynthesis, has been shown in the hippocampi of rats fed a KD. In addition, rats fed a $\mathrm{KD}$ produce less $\mathrm{H}_{2} \mathrm{O}_{2}$ than controls, suggesting functional improvements as a result of consuming a KD. It has been suggested that activation of the Nrf2 transcription factor plays an important role in the enhanced biosynthesis of GSH by KDs [107]. Although the exact mechanism by which a KD provides neuroprotection remains unclear, the previously mentioned results suggest that restoring the antioxidant system may be linked to the anticonvulsant properties of a KD.

\author{
Abbreviations \\ AEDs: Antiepileptic drugs \\ CAT: Catalase \\ EGCG: Epigallocatechin-3-gallate \\ GEPRs: Genetically epilepsy-prone rats \\ GCL: Glutamate cysteine ligase \\ GPx: Glutathione peroxidase \\ GR: Glutathione reductase \\ GSH: Reduced form of glutathione \\ GSSG: Oxidized form of glutathione \\ GST: Glutathione S-transferase \\ $\mathrm{H}_{2} \mathrm{O}_{2}$ : Hydrogen peroxide \\ KA: Kainic acid \\ KD: Ketogenic diet \\ $\mathrm{HO}^{\circ}$ : Hydroxyl radical \\ PTZ: Pentylenetetrazol \\ ROS: Reactive oxygen species \\ SOD: Superoxide dismutase \\ Se: $\quad$ Selenium \\ TCA: Tricarboxylic acid cycle \\ TLE: Temporal lobe epilepsy \\ TMT: Trimethyltin \\ TPM: Topiramate.
}

\section{Conflict of Interests}

The authors declare that there is no conflict of interests regarding the publication of this paper. 


\section{Authors' Contribution}

Noemí Cárdenas-Rodríguez and Elvia Coballase-Urrutia contributed equally to this work.

\section{Acknowledgments}

The authors appreciate the financial support received from Protocols 034/2013, 014/2012, 04/2013, and 016/2014 of the Pediatrics National Institute as well as the technical assistance of Ms. Sergio Humberto Larios-Godínez.

\section{References}

[1] E. Beit-Yannai, R. Kohen, M. Horowitz, V. Trembovler, and E. Shohami, "Changes of biological reducing activity in rat brain following closed head injury: a cyclic voltammetry study in normal and heat-acclimated rats," Journal of Cerebral Blood Flow and Metabolism, vol. 17, no. 3, pp. 273-279, 1997.

[2] P. G. Winyard, C. J. Moody, and C. Jacob, "Oxidative activation of antioxidant defence," Trends in Biochemical Sciences, vol. 30, no. 8, pp. 453-461, 2005.

[3] J. Folbergrová and W. S. Kunz, "Mitochondrial dysfunction in epilepsy," Mitochondrion, vol. 12, no. 1, pp. 35-40, 2012.

[4] B. Halliwell and M. Gutteridge, Free Radicals in Biology and Medicine, Oxford University Press, New York, NY, USA, 3rd edition, 1999.

[5] N. Cárdenas-Rodríguez and J. Pedraza-Chaverri, "Especies reactivas de oxígeno y sistemas antioxidantes: aspectos básicos," Educación Química, vol. 17, no. 2, pp. 164-173, 2006.

[6] R. Brigelius-Flohé, "Tissue-specific functions of individual glutathione peroxidases," Free Radical Biology and Medicine, vol. 27, no. 9-10, pp. 951-965, 1999.

[7] F.-F. Chu, R. S. Esworthy, and J. H. Doroshow, "Role of Sedependent glutathione peroxidases in gastrointestinal inflammation and cancer," Free Radical Biology and Medicine, vol. 36, no. 12, pp. 1481-1495, 2004.

[8] S. A. A. Comhair and S. C. Erzurum, "The regulation and role of extracellular glutathione peroxidase," Antioxidants and Redox Signaling, vol. 7, no. 1-2, pp. 72-79, 2005.

[9] H. Imai and Y. Nakagawa, "Biological significance of phospholipid hydroperoxide glutathione peroxidase (PHGPx, GPx4) in mammalian cells," Free Radical Biology and Medicine, vol. 34, no. 2, pp. 145-169, 2003.

[10] R. Untucht-Grau, R. H. Schirmer, I. Schirmer, and R. L. Krauth-Siegel, "Glutathione reductase from human erythrocytes. Amino-acid sequence of the structurally known FADbinding domain," European Journal of Biochemistry, vol. 120, no. 2, pp. 407-419, 1981.

[11] E. D. Harris, "Regulation of antioxidant enzymes," FASEB Journal, vol. 6, no. 9, pp. 2675-2683, 1992.

[12] R. Sharma, Y. Yang, A. Sharma, S. Awasthi, and Y. C. Awasthi, "Antioxidant role of glutathione S- transferases: protection against oxidant toxicity and regulation of stress-mediated apoptosis," Antioxidants and Redox Signaling, vol. 6, no. 2, pp. 289300, 2004.

[13] L. G. Higgins and J. D. Hayes, "Mechanisms of induction of cytosolic and microsomal glutathione transferase (GST) genes by xenobiotics and pro-inflammatory agents," Drug Metabolism Reviews, vol. 43, no. 2, pp. 92-137, 2011.
[14] A. Oakley, "Glutathione transferases: a structural perspective," Drug Metabolism Reviews, vol. 43, no. 2, pp. 138-151, 2011.

[15] P. Szot, "Common factors among Alzheimer's disease, Parkinson's disease, and epilepsy: possible role of the noradrenergic nervous system," Epilepsia, vol. 53, no. 1, pp. 61-66, 2012.

[16] T. Uchihara, H. Kondo, K. Kosaka, and H. Tsukagoshi, "Selective loss of nigral neurons in Alzheimer's disease: a morphometric study," Acta Neuropathologica, vol. 83, no. 3, pp. 271-276, 1992.

[17] P. J. McMillan, S. S. White, A. Franklin et al., "Differential response of the central noradrenergic nervous system to the loss of locus coeruleus neurons in Parkinson's disease and Alzheimer's disease," Brain Research, vol. 1373, pp. 240-252, 2011.

[18] L. Dodds, J. Chen, K. Berggren, and J. Fox, "Characterization of striatal neuronal loss and atrophy in the R6/2 mouse model of Huntington's disease," PLoS Currents, vol. 6, pp. 1-6, 2014.

[19] D. Bano, F. Zanetti, Y. Mende, and P. Nicotera, "Neurodegenerative processes in Huntington's disease," Cell Death \& Disease, vol. 2, no. 11, pp. e228-e241, 2011.

[20] E. Pollari, G. Goldsteins, G. Bart, J. Koistinaho, and R. Giniatullin, "The role of oxidative stress in degeneration of the neuromuscular junction in amyotrophic lateral sclerosis," Frontiers in Cellular Neuroscience, vol. 13, no. 8, article 131, 2014.

[21] R. Ahdab, A. Créange, C. Saint-Val, W. H. Farhat, and J. P. Lefaucheur, "Rapidly progressive amyotrophic lateral sclerosis initially masquerading as a demyelinating neuropathy," Neurophysiologie Clinique, vol. 43, no. 3, pp. 181-187, 2013.

[22] M. R. Turner, R. Bowser, L. Bruijn et al., "Mechanisms, models and biomarkers in amyotrophic lateral sclerosis," Amyotrophic Lateral Sclerosis and Frontotemporal Degeneration, vol. 14, no. 1, pp. 19-32, 2013.

[23] A. H. Koeppen, "Friedreich's ataxia: Pathology, pathogenesis, and molecular genetics," Journal of the Neurological Sciences, vol. 303, no. 1-2, pp. 1-12, 2011.

[24] A. H. Koeppen, J. A. Morral, R. D. McComb, and P. J. Feustel, "The neuropathology of late-onset Friedreich's ataxia," Cerebellum, vol. 10, no. 1, pp. 96-103, 2011.

[25] N. Huusko, C. Römer, X. E. Ndode-Ekane, K. Lukasiuk, and A. Pitkänen, "Loss of hippocampal interneurons and epileptogenesis: a comparison of two animal models of acquired epilepsy," Brain Structure \& Function, 2013.

[26] D. G. Fujikawa, H. H. Itabashi, A. Wu, and S. S. Shinmei, "Status epilepticus-induced neuronal loss in humans without systemic complications or epilepsy," Epilepsia, vol. 41, no. 8, pp. 981-991, 2000.

[27] C. Gavrilovici, E. Pollock, M. Everest, and M. O. Poulter, "The loss of interneuron functional diversity in the piriform cortex after induction of experimental epilepsy," Neurobiology of Disease, vol. 48, no. 3, pp. 317-328, 2012.

[28] R. Dringen, "Metabolism and functions of glutathione in brain," Progress in Neurobiology, vol. 62, no. 6, pp. 649-671, 2000.

[29] A. Nunomura, P. I. Moreira, R. J. Castellani et al., "Oxidative damage to RNA in aging and neurodegenerative disorders," Neurotoxicity Research, vol. 22, no. 3, pp. 231-248, 2012.

[30] G. Perry, A. Nunomura, K. Hirai et al., "Is oxidative damage the fundamental pathogenic mechanism of Alzheimer's and other neurodegenerative diseases?" Free Radical Biology and Medicine, vol. 33, no. 11, pp. 1475-1479, 2002.

[31] M. E. Anderson, "Glutathione: an overview of biosynthesis and modulation," Chemico-Biological Interactions, vol. 111, pp. 1-14, 1998. 
[32] T. S. Chen, J. P. Richie Jr., and C. A. Lang, "The effect of aging on glutathione and cysteine levels in different regions of the mouse brain," Proceedings of the Society for Experimental Biology and Medicine, vol. 190, no. 4, pp. 399-402, 1989.

[33] L. C. Abbott, H. H. Nejad, W. G. Bottje, and A. S. Hassan, "Glutathione levels in specific brain regions of genetically epileptic $(\mathrm{tg} / \mathrm{tg})$ mice," Brain Research Bulletin, vol. 25, no. 4, pp. 629-631, 1990.

[34] M. E. Anderson, M. Underwood, R. J. Bridges, and A. Meister, "Glutathione metabolism at the blood-cerebrospinal fluid barrier," FASEB Journal, vol. 3, no. 13, pp. 2527-2531, 1989.

[35] X. F. Wang and M. S. Cynader, "Astrocytes provide cysteine to neurons by releasing glutathione," Journal of Neurochemistry, vol. 74, no. 4, pp. 1434-1442, 2000.

[36] "The dissection of a degenerative disease," in Proceedings of Four Round-Table Conferences on the Pathogenesis of Batten's Disease (Neuronal Ceroid-Lipofuscinosis), W. Zeman and J. A. Rider, Eds., American Elsevier Publishing, New York, NY, USA, 1975.

[37] S. L. Marklund, P. Santavuori, and T. Westermarck, "Superoxide dismutase, catalase and glutathione peroxidase in infantile, late infantile and juvenile neuronal ceroid-lipofuscinosis," Clinica Chimica Acta, vol. 116, no. 2, pp. 191-198, 1981.

[38] H. S. Garg, Y. C. Awasthi, W. A. Neff, N. H. Ansari, and S. K. Srivastava, "Studies in neuronal ceroid lipofuscinosis: enzymes of liver and brain tissues involved in the defense against oxidative damage," Journal of Neuroscience Research, vol. 7, no. 3, pp. 305-311, 1982.

[39] R. K. B. Pearce, A. Owen, S. Daniel, P. Jenner, and C. D. Marsden, "Alterations in the distribution of glutathione in the substantia nigra in Parkinson's disease," Journal of Neural Transmission, vol. 104, no. 6-7, pp. 661-677, 1997.

[40] S. Bharath, M. Hsu, D. Kaur, S. Rajagopalan, and J. K. Andersen, "Glutathione, iron and Parkinson's disease," Biochemical Pharmacology, vol. 64, no. 5-6, pp. 1037-1048, 2002.

[41] M. Smeyne and R. J. Smeynen, "Glutathione metabolism and Parkinson's disease," Free Radical Biology and Medicine, vol. 62, pp. 13-25, 2013.

[42] J. Clausen, "Demential syndromes and the lipid metabolism," Acta Neurologica Scandinavica, vol. 70, no. 5, pp. 345-355, 1984.

[43] J. D. Adams, L. K. Klaidman, I. N. Odunze, H. C. Shen, and C. A. Miller, "Alzheimer's and Parkinson's disease," Molecular and Chemical Neuropathology, vol. 14, no. 3, pp. 213-226, 1991.

[44] C. Cecchi, S. Latorraca, S. Sorbi et al., "Gluthatione level is altered in lymphoblasts from patients with familial Alzheimer's disease," Neuroscience Letters, vol. 275, no. 2, pp. 152-154, 1999.

[45] H. Liu, L. E. Harrell, S. Shenvi, T. Hagen, and R.-M. Liu, "Gender differences in glutathione metabolism in Alzheimer's disease," Journal of Neuroscience Research, vol. 79, no. 6, pp. 861-867, 2005.

[46] L. Chi, Y. Ke, C. Luo, D. Gozal, and R. Liu, "Depletion of reduced glutathione enhances motor neuron degeneration in vitro and in vivo," Neuroscience, vol. 144, no. 3, pp. 991-1003, 2007.

[47] S. Przedborski, D. M. Donaldson, P. L. Murphy et al., "Blood superoxide dismutase, catalase and glutathione peroxidase activities in familial and sporadic amyotrophic lateral sclerosis," Neurodegeneration, vol. 5, no. 1, pp. 57-64, 1996.

[48] R. Moumen, A. Nouvelot, D. Duval, B. Lechevalier, and F. Viader, "Plasma superoxide dismutase and glutathione peroxidase activity in sporadic amyotrophic lateral sclerosis," Journal of the Neurological Sciences, vol. 151, no. 1, pp. 35-39, 1997.
[49] S. Apostolski, Z. Marinković, A. Nikolić, D. Blagojević, M. B. Spasić, and A. Michael Michelson, "Glutathione peroxidase in amyotrophic lateral sclerosis: The effects of selenium supplementation," Journal of Environmental Pathology, Toxicology and Oncology, vol. 17, no. 3-4, pp. 325-329, 1998.

[50] S. Przedborski, D. Donaldson, M. Jakowec et al., "Brain superoxide dismutase, catalase, and glutathione peroxidase activities in amyotrophic lateral sclerosis," Annals of Neurology, vol. 39, no. 2, pp. 158-165, 1996.

[51] J. Sian, D. T. Dexter, A. J. Lees et al., "Alterations in glutathione levels in Parkinson's disease and other neurodegenerative disorders affecting basal ganglia," Annals of Neurology, vol. 36, no. 3, pp. 348-355, 1994.

[52] N. Klepac, M. Relja, R. Klepac, S. Hećimović, T. Babić, and V. Trkulja, "Oxidative stress parameters in plasma of Huntington's disease patients, asymptomatic Huntington's disease gene carriers and healthy subjects: a cross-sectional study," Journal of Neurology, vol. 254, no. 12, pp. 1676-1683, 2007.

[53] Y. S. Choo, Z. Mao, G. V. Johnson, and M. Lesort, "Increased glutathione levels in cortical and striatal mitochondria of the R6/2 Huntington's disease mouse model," Neuroscience Letters, vol. 386, no. 1, pp. 63-68, 2005.

[54] P. Kumar, H. Kalonia, and A. Kumar, "Protective effect of sesamol against 3-nitropropionic acid-induced cognitive dysfunction and altered glutathione redox balance in rats," Basic and Clinical Pharmacology and Toxicology, vol. 107, no. 1, pp. 577-582, 2010

[55] T. W. Strine, R. Kobau, D. P. Chapman, D. J. Thurman, P. Price, and L. S. Balluz, "Psychological distress, comorbidities, and health behaviors among U.S. adults with seizures: results from the 2002 National Health Interview Survey," Epilepsia, vol. 46, no. 7, pp. 1133-1139, 2005.

[56] S.-J. Chang and B.-C. Yu, "Mitochondrial matters of the brain: Mitochondrial dysfunction and oxidative status in epilepsy," Journal of Bioenergetics and Biomembranes, vol. 42, no. 6, pp. 457-459, 2010.

[57] L.-P. Liang and M. Patel, "Seizure-induced changes in mitochondrial redox status," Free Radical Biology and Medicine, vol. 40, no. 2, pp. 316-322, 2006.

[58] A. J. Bruce and M. Baudry, "Oxygen free radicals in rat limbic structures after kainate-induced seizures," Free Radical Biology and Medicine, vol. 18, no. 6, pp. 993-1002, 1995.

[59] M. R. Gluck, E. Jayatilleke, S. Shaw, A. J. Rowan, and V. Haroutunian, "CNS oxidative stress associated with the kainic acid rodent model of experimental epilepsy," Epilepsy Research, vol. 39, no. 1, pp. 63-71, 2000.

[60] Y.-C. Chuang, "Mitochondrial dysfunction and oxidative stress in seizure-induced neuronal cell death," Acta Neurologica Taiwanica, vol. 19, no. 1, pp. 3-15, 2010.

[61] L. P. Liang, Y. S. Ho, and M. Patel, "Mitochondrial superoxide production in kainate-induced hippocampal damage," Neuroscience, vol. 101, no. 3, pp. 563-570, 2000.

[62] K. Sudha, A. V. Rao, and A. Rao, "Oxidative stress and antioxidants in epilepsy," Clinica Chimica Acta, vol. 303, no. 1-2, pp. 19-24, 2001.

[63] M. R. Ashrafi, R. Shabanian, A. Abbaskhanian et al., "Selenium and intractable epilepsy: is there any correlatio?" Pediatric Neurology, vol. 36, no. 1, pp. 25-29, 2007.

[64] A. Yüksel, M. Cengiz, M. Seven, and T. Ulutin, "Changes in the antioxidant system in epileptic children receiving antiepileptic drugs: two-year prospective studies," Journal of Child Neurology, vol. 16, no. 8, pp. 603-606, 2001. 
[65] J. W. Dailey, C. E. Reigel, P. K. Mishra, and P. C. Jobe, "Neurobiology of seizure predisposition in the genetically epilepsy-prone rat," Epilepsy Research, vol. 3, no. 1, pp. 3-17, 1989.

[66] E.-J. Shin, K. H. Ko, W.-K. Kim et al., "Role of glutathione peroxidase in the ontogeny of hippocampal oxidative stress and kainate seizure sensitivity in the genetically epilepsy-prone rats," Neurochemistry International, vol. 52, no. 6, pp. 1134-1147, 2008.

[67] R. S. Dyer, T. L. Deshields, and W. F. Wonderlin, "Trimethyltininduced changes in gross morphology of the hippocampus," Neurobehavioral Toxicology and Teratology, vol. 4, no. 2, pp. 141$147,1982$.

[68] K. Ogita, Y. Nitta, M. Watanabe et al., "In vivo activation of cJun N-terminal kinase signaling cascade prior to granule cell death induced by trimethyltin in the dentate gyrus of mice," Neuropharmacology, vol. 47, no. 4, pp. 619-630, 2004.

[69] N. Ishida, M. Akaike, S. Tsutsumi et al., "Trimethyltin syndrome as a hippocampal degeneration model: temporal changes and neurochemical features of seizure susceptibility and learning impairment," Neuroscience, vol. 81, no. 4, pp. 1183-1191, 1997.

[70] E.-J. Shin, S. K. Suh, Y. K. Lim et al., "Ascorbate attenuates trimethyltin-induced oxidative burden and neuronal degeneration in the rat hippocampus by maintaining glutathione homeostasis," Neuroscience, vol. 133, no. 3, pp. 715-727, 2005.

[71] R. Nagashima, S. Sano, N. Q. Huong, T. Shiba, and K. Ogita, "Enhanced expression of glutathione S-transferase in the hippocampus following acute treatment with trimethyltin in vivo," Journal of Pharmacological Sciences, vol. 113, no. 3, pp. 267-270, 2010.

[72] N. Cárdenas-Rodríguez, E. Coballase-Urrutia, L. RiveraEspinosa et al., "Modulation of antioxidant enzymatic activities by certain antiepileptic drugs (valproic acid, oxcarbazepine, and topiramate): evidence in humans and experimental models," Oxidative Medicine and Cellular Longevity, vol. 2013, Article ID 598493, 8 pages, 2013.

[73] S. A. Hamed and M. M. Abdellah, "Trace elements and electrolytes homeostasis and their relation to antioxidant enzyme activity in brain hyperexcitability of epileptic patients," Journal of Pharmacological Sciences, vol. 96, no. 4, pp. 349-359, 2004.

[74] K. H. Schulpis, C. Lazaropoulou, S. Regoutas et al., "Valproic acid monotherapy induces DNA oxidative damage," Toxicology, vol. 217, no. 2-3, pp. 228-232, 2006.

[75] A. O. Varoglu, A. Yildirim, R. Aygul, O. L. Gundogdu, and Y. N. Sahin, "Effects of valproate, carbamazepine, and levetiracetam on the antioxidant and oxidant systems in epileptic patients and their clinical importance," Clinical Neuropharmacology, vol. 33, no. 3, pp. 155-157, 2010.

[76] C. S. Liu, H. M. Wu, S. H. Kao, and Y. H. Wei, "Serum trace elements, glutathione, copper/zinc superoxide dismutase, and lipid peroxidation in epileptic patients with phenytoin or carbamazepine monotherapy," Clinical Neuropharmacology, vol. 21, no. 1, pp. 62-64, 1998.

[77] E.-J. Shin, J. H. Jeong, Y. H. Chung et al., "Role of oxidative stress in epileptic seizures," Neurochemistry International, vol. 59, no. 2, pp. 122-137, 2011.

[78] V. Niketic, S. Ristic, Z. S. Saicic, M. Spasic, B. Buzadzic, and M. Stojkovic, "Activities of antioxidant enzymes and formation of the glutathione adduct of hemoglobin (hb ASSG) in epileptic patients with long-term antiepileptic therapy," Farmaco, vol. 50, no. 11, pp. 811-813, 1995.

[79] D. Lindhout, R. J. E. A. Hoppener, and H. Meinardi, “Teratogenicity of antiepileptic drug combinations with special emphasis on epoxidation (of carbamazepine)," Epilepsia, vol. 25, no. 1, pp. 77-83, 1984.

[80] R. Hernández, M. de los Ángeles Fernández, G. Miranda, and R. Suástegui-Román, "Decrease of folic acid and cognitive alterations in patients with epilepsy treated with phenytoin or carmabazepine, pilot study," Revista de Investigacion Clinica, vol. 57, no. 4, pp. 522-531, 2005.

[81] H. E. Shannon and P. L. Love, "Effects of antiepileptic drugs on attention as assessed by a five-choice serial reaction time task in rats," Epilepsy and Behavior, vol. 7, no. 4, pp. 620-628, 2005.

[82] H. Jokeit, G. Krämer, and A. Ebner, "Do antiepileptic drugs accelerate forgetting?” Epilepsy \& Behavior, vol. 6, no. 3, pp. 430-432, 2005.

[83] A. M. Naidech, K. T. Kreiter, N. Janjua et al., "Phenytoin exposure is associated with functional and cognitive disability after subarachnoid hemorrhage," Stroke, vol. 36, no. 3, pp. 583587, 2005.

[84] M. Gupta, S. Aneja, and K. Kohli, "Add-on melatonin improves quality of life in epileptic children on valproate monotherapy: a randomized, double-blind, placebo-controlled trial," Epilepsy and Behavior, vol. 5, no. 3, pp. 316-321, 2004.

[85] M. Gupta, Y. K. Gupta, S. Agarwal, S. Aneja, and K. Kohli, "A randomized, double-blind, placebo controlled trial of melatonin add-on therapy in epileptic children on valproate monotherapy: effect on glutathione peroxidase and glutathione reductase enzymes," British Journal of Clinical Pharmacology, vol. 58, no. 5, pp. 542-547, 2004.

[86] M. Gupta, Y. K. Gupta, S. Agarwal, S. Aneja, M. Kalaivani, and K. Kohli, "Effects of add-on melatonin administration on antioxidant enzymes in children with epilepsy taking carbamazepine monotherapy: a randomized, double-blind, placebocontrolled trial," Epilepsia, vol. 45, no. 12, pp. 1636-1639, 2004.

[87] M. Gupta, S. Aneja, and K. Kohli, "Add-on melatonin improves sleep behavior in children with epilepsy: randomized, doubleblind, placebo-controlled trial," Journal of Child Neurology, vol. 20, no. 2, pp. 112-115, 2005.

[88] H. S. White, M. D. Smith, and K. S. Wilcox, "Mechanisms of action of antiepileptic drugs," International Review of Neurobiology, vol. 81, pp. 85-110, 2007.

[89] V. A. Yürekli and M. Naziroğlu, "Selenium and topiramate attenuates blood oxidative toxicity in patients with epilepsy: a clinical pilot study," Biological Trace Element Research, vol. 152, no. 2, pp. 180-186, 2013.

[90] S. Kutluhan, M. Naziroğlu, Ö. Çelik, and M. Yilmaz, "Effects of selenium and topiramate on lipid peroxidation and antioxidant vitamin levels in blood of pentylentetrazol-induced epileptic rats," Biological Trace Element Research, vol. 129, no. 1-3, pp. 181189, 2009.

[91] Q. Guo, B. Zhao, M. Li, S. Shen, and X. Wenjuan, "Studies on protective mechanisms of four components of green tea polyphenols against lipid peroxidation in synaptosomes," Biochimica et Biophysica Acta, vol. 1304, no. 3, pp. 210-222, 1996.

[92] Y. Kuroda and Y. Hara, "Antimutagenic and anticarcinogenic activity of tea polyphenols," Mutation Research, vol. 436, no. 1, pp. 69-97, 1999.

[93] E. Tedeschi, H. Suzuki, and M. Menegazzi, "Antiinflammatory action of EGCG, the main component of green tea, through STAT-1 inhibition," Annals of the New York Academy of Sciences, vol. 973, pp. 435-437, 2002.

[94] T. Xie, W.-P. Wang, Z.-F. Mao et al., "Effects of epigallocatechin3-gallate on pentylenetetrazole-induced kindling, cognitive 
impairment and oxidative stress in rats," Neuroscience Letters, vol. 516, no. 2, pp. 237-241, 2012.

[95] R. F. Tayyem, D. D. Heath, W. K. Al-Delaimy, and C. L. Rock, "Curcumin content of turmeric and curry powders," Nutrition and Cancer, vol. 55, no. 2, pp. 126-131, 2006.

[96] T. Ahmed and A.-H. Gilani, "Inhibitory effect of curcuminoids on acetylcholinesterase activity and attenuation of scopolamine-induced amnesia may explain medicinal use of turmeric in Alzheimer's disease," Pharmacology Biochemistry and Behavior, vol. 91, no. 4, pp. 554-559, 2009.

[97] K. H. Reeta, J. Mehla, and Y. K. Gupta, "Curcumin is protective against phenytoin-induced cognitive impairment and oxidative stress in rats," Brain Research, vol. 1301, pp. 52-60, 2009.

[98] Y. K. Gupta, S. Briyal, and M. Sharma, "Protective effect of curcumin against kainic acid induced seizures and oxidative stress in rats," Indian Journal of Physiology and Pharmacology, vol. 53, no. 1, pp. 39-46, 2009.

[99] H. J. Shin, J. Y. Lee, E. Son et al., "Curcumin attenuates the kainic acid-induced hippocampal cell death in the mice," Neuroscience Letters, vol. 416, no. 1, pp. 49-54, 2007.

[100] A. Jyoti, P. Sethi, and D. Sharma, "Curcumin protects against electrobehavioral progression of seizures in the iron-induced experimental model of epileptogenesis," Epilepsy and Behavior, vol. 14, no. 2, pp. 300-308, 2009.

[101] N. Bharal, K. Sahaya, S. Jain, P. K. Mediratta, and K. K. Sharma, "Curcumin has anticonvulsant activity on increasing current electroshock seizures in mice," Phytotherapy Research, vol. 22, no. 12, pp. 1660-1664, 2008.

[102] X. Peng, L. Wang, G. Chen, and X. Wang, "Dynamic expression of adenylate kinase 2 in the hippocampus of pilocarpine model rats," Journal of Molecular Neuroscience, vol. 47, no. 1, pp. 150157, 2012.

[103] P. Du, X. Li, H.-J. Lin et al., "Curcumin inhibits amygdaloid kindled seizures in rats," Chinese Medical Journal, vol. 122, no. 12, pp. 1435-1438, 2009.

[104] P. G. Sullivan, N. A. Rippy, K. Dorenbos, R. C. Concepcion, A. K. Agarwal, and J. M. Rho, "The ketogenic diet increases mitochondrial uncoupling protein levels and activity," Annals of Neurology, vol. 55, no. 4, pp. 576-580, 2004.

[105] K. J. Bough, J. Wetherington, B. Hassel et al., "Mitochondrial biogenesis in the anticonvulsant mechanism of the ketogenic diet," Annals of Neurology, vol. 60, no. 2, pp. 223-235, 2006.

[106] S. G. Jarrett, J. B. Milder, L.-P. Liang, and M. Patel, “The ketogenic diet increases mitochondrial glutathione levels," Journal of Neurochemistry, vol. 106, no. 3, pp. 1044-1051, 2008.

[107] J. Milder and M. Patel, "Modulation of oxidative stress and mitochondrial function by the ketogenic diet," Epilepsy Research, vol. 100, no. 3, pp. 295-303, 2012.

[108] L. Holtman, E. A. van Vliet, C. Appeldoorn et al., "Glutathione pegylated liposomalmethylprednisolone administration afterthe early phase of status epilepticus did notmodify epileptogenesis in the rat," Epilepsy Research, vol. 108, no. 3, pp. 396-404, 2014.

[109] T. Eid, A. Ghosh, Y. Wang et al., "s," Brain, vol. 131, part 8, pp. 2061-2070, 2008.

[110] T. M. Melø, A. Nehlig, and U. Sonnewald, "Metabolism is normal in astrocytes in chronically epileptic rats: a 13C NMR study of neuronal-glial interactions in a model of temporal lobe epilepsy," Journal of Cerebral Blood Flow and Metabolism, vol. 25, no. 10, pp. 1254-1264, 2005.
[111] O. B. Smeland, M. G. Hadera, T. S. Mcdonald, U. Sonnewald, and K. Borges, "Brain mitochondrial metabolic dysfunction and glutamate level reduction in the pilocarpine model of temporal lobe epilepsy in mice," Journal of Cerebral Blood Flow and Metabolism, vol. 33, no. 7, pp. 1090-1097, 2013.

[112] H. V. N. Júnior, M. M. D. F. Fonteles, and R. M. D. De Freitas, "Acute seizure activity promotes lipid peroxidation, increased nitrite levels and adaptive pathways against oxidative stress in the frontal cortex and striatum," Oxidative Medicine and Cellular Longevity, vol. 2, no. 3, pp. 130-137, 2009.

[113] S. Peternel, K. Pilipović, and G. Župan, "Seizure susceptibility and the brain regional sensitivity to oxidative stress in male and female rats in the lithium-pilocarpine model of temporal lobe epilepsy," Progress in Neuro-Psychopharmacology and Biological Psychiatry, vol. 33, no. 3, pp. 456-462, 2009.

[114] S. Tejada, A. Sureda, C. Roca, A. Gamundí, and S. Esteban, "Antioxidant response and oxidative damage in brain cortex after high dose of pilocarpine," Brain Research Bulletin, vol. 71, no. 4, pp. 372-375, 2007.

[115] K. Ryan, L. P. Liang, C. Rivard, and M. Patel, “Temporal and spatial increase of reactive nitrogen species in the kainate model of temporal lobe epilepsy," Neurobiology of Disease, vol. 64, pp. $8-15,2014$.

[116] J. López, M. E. González, L. Lorigados, L. Morales, G. Riverón, and J. Y. Bauzá, "Oxidative stress markers in surgically treated patients with refractory epilepsy," Clinical Biochemistry, vol. 40, no. 5-6, pp. 292-298, 2007.

[117] A. Yüzbaşioğlu, H. Karataş, Y. Gürsoy-Özdemir et al., "Changes in the expression of selenoproteins in mesial temporal lobe epilepsy patients," Cellular and Molecular Neurobiology, vol. 29, no. 8, pp. 1223-1231, 2009.

[118] S. G. Mueller, A. H. Trabesinger, P. Boesiger, and H. G. Wieser, "Brain glutathione levels in patients with epilepsy measured by in vivo ${ }^{1}$ H-MRS," Neurology, vol. 57, no. 8, pp. 1422-1427, 2001. 


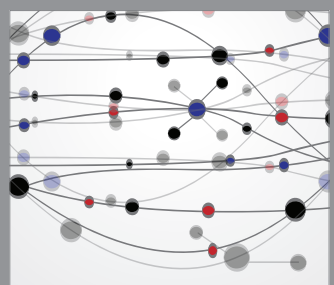

The Scientific World Journal
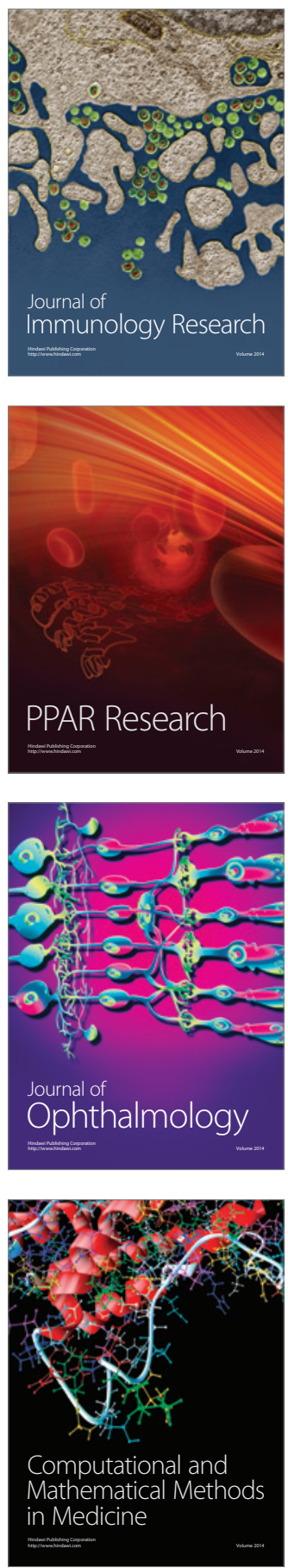

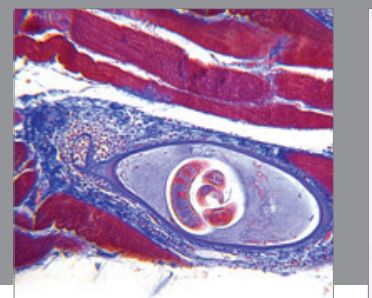

Gastroenterology

Research and Practice
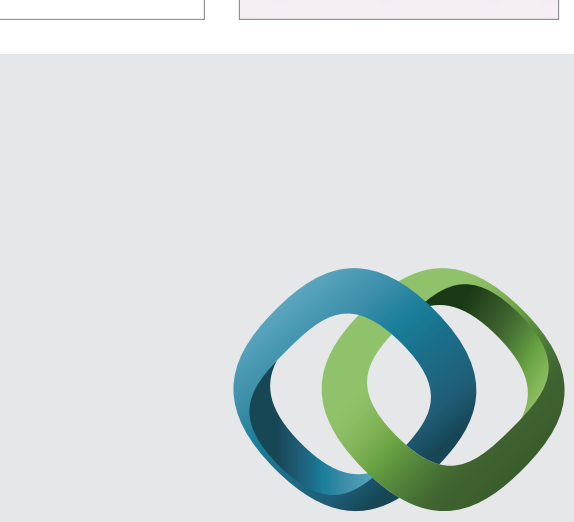

\section{Hindawi}

Submit your manuscripts at

http://www.hindawi.com
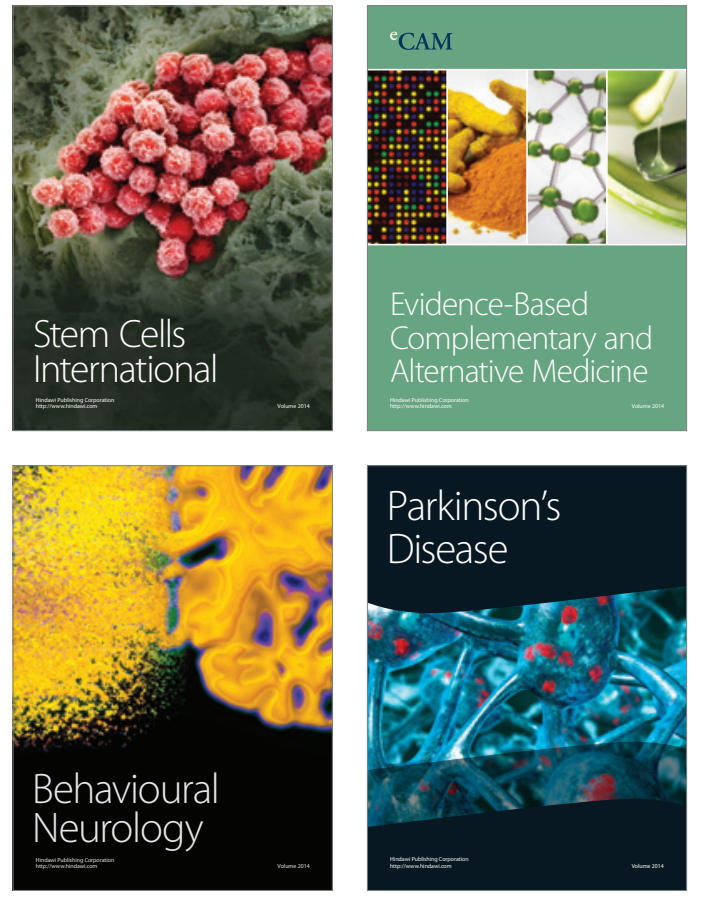
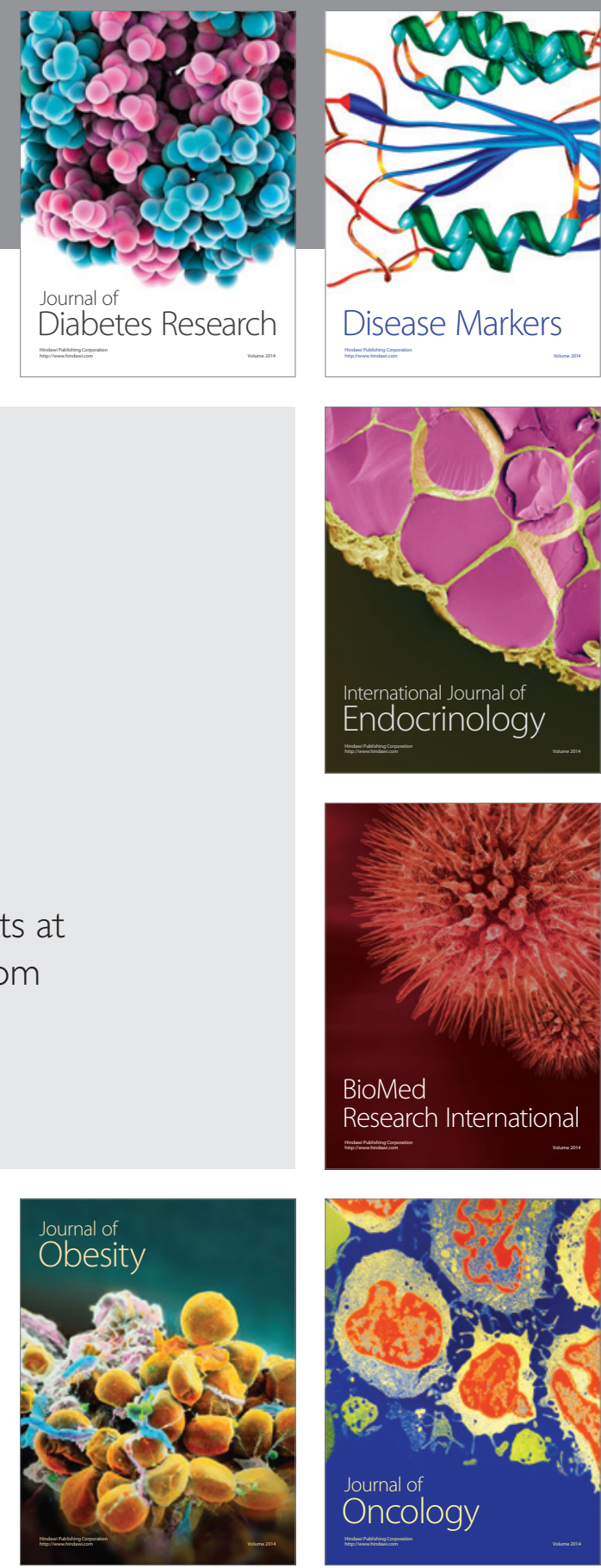

Disease Markers
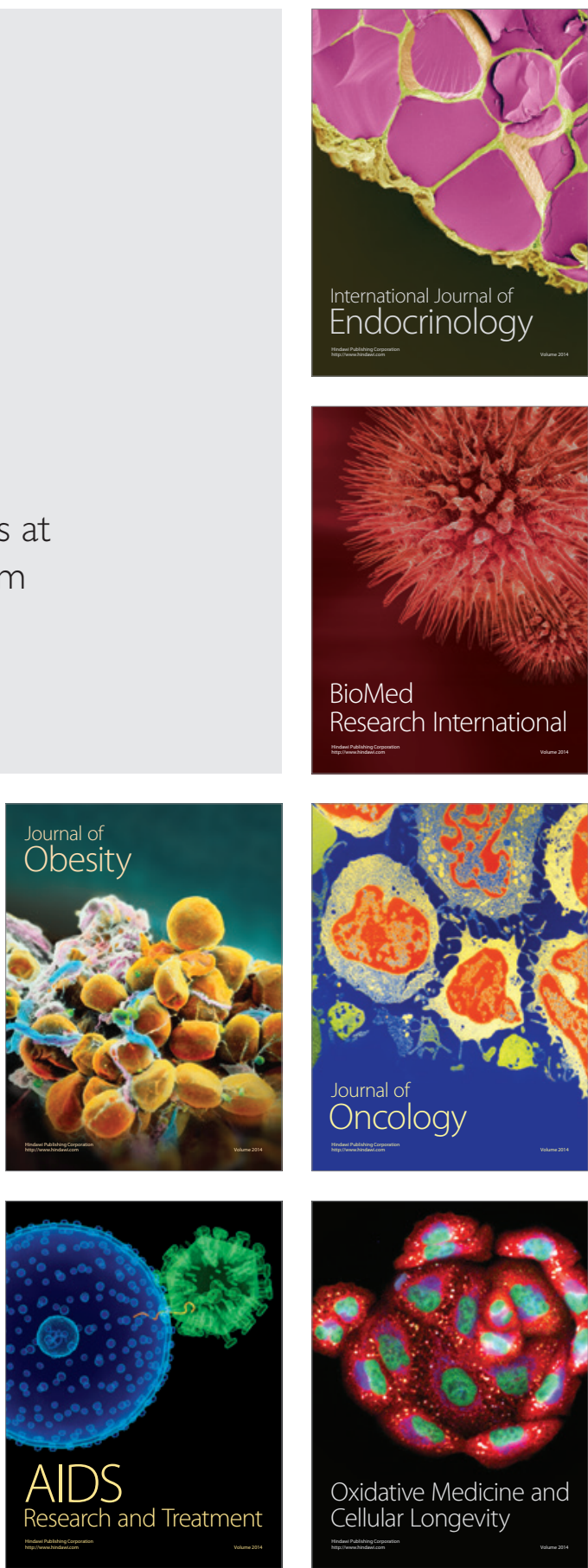